\title{
Malignancies following lung transplantation: the Portuguese experience
}

\begin{abstract}
Malignancy is an important complication after lung transplantation (LT), which is related to common risk factors in these patients, oncogenic viruses and immunosuppression therapy (IST). We retrospectively analyzed all cases of malignancy in the 182 patients that underwent LT between June 2001 and December 2017 in Portugal. We noticed an incidence of $7.6 \%$, similar to that described in the literature, with a mean age of 53 years and a mean time after LT of 25 months. As in other series, the most common types of cancer were skin cancer $(2.7 \%)$, post transplant lymphoproliferative disorders $(2.2 \%)$ and lung cancer $(1.6 \%)$. Unexpectedly we found an important incidence of gastric cancer $(1,1 \%)$ not previously described in the literature that we relate to the elevated incidence of this cancer in our country. All patients underwent treatment and IST adjustments, according to a multidisciplinary team approach. In this series, 4 patients died due to cancer $(33.3 \%)$ with a median survival of 26 months. We conclude that cancer is an important complication after LT and further investigation and awareness is needed to optimize diagnosis and management of this condition.
\end{abstract}

Keywords: optimize diagnosis, skin cancer, lymphoproliferative disorders, Epstein-Barr virus, malignancy
Volume 10 Issue 4 - 2019

V Caldeira,' S Silva,' N Caires,' N Murinello,' AS Santos,' L Semedo,' J Cardoso,' J Fragata 'Department of Pneumology, Hospital Santa Marta, Portugal

${ }^{2}$ Department of Cardiothoracic, Hospital Santa Marta, Portugal

Correspondence: V Caldeira, Department of Pneumology, Hospital Santa Marta, Lisbon, Portugal,

Email vania.medicina@gmail.com

Received: August 30, 2019 | Published: September 19, 2019
Abbreviations: LT, lung transplantation; ISHLT, international society for heart and lung transplantation; COPD, chronic obstructive pulmonary disease; IPF, idiopathic pulmonary fibrosis; PTDL, posttransplant lymphoproliferative disorders; EBV, Epstein-Barr virus; $\mathrm{LCH}$, langerhans cell histiocytosis; $\mathrm{SCC}$, squamous cell carcinoma; ATG, anti-thymocyte globulin

\section{Introduction}

Malignancy is a recognized complication of lung transplantation (LT) and other solid organ transplantation. According to International Society for Heart and Lung Transplantation (ISHLT) 2017 report, cancer became an increasingly common diagnosis after the first year. In the period between 3 and 5 years after LT it accounts for $13.3 \%$ of deaths and this value increases after the 5 years. ${ }^{1-4}$ In Chronic Obstructive Pulmonary Disease (COPD) patients that underwent LT the risk of cancer other than skin cancer is 5-fold higher than in general population. ${ }^{5}$

The most common types of cancer are skin cancer and post transplant lymphoproliferative disorders (PTLD). The last one being more frequent in the first year after LT. ${ }^{1,6,7}$ However, lung cancer is also an important problem after LT and more frequently occurs in the native lung of single LT patients for COPD or Idiopathic Pulmonary Fibrosis (IPF) with a referred prevalence of $0.1-2.3 \% .{ }^{8}$ In the last years there is also an increasing awareness for the presence of unexpected lung cancer in the explanted lungs. ${ }^{9}$ Immunosuppression therapy (IST) is both a risk factor for earlier cancer and a challenge to manage after diagnosis of malignancy. Other risk factors are oncogenic viruses as Epstein-Barr virus (EBV), increasing age of both receptors and donors, smoking or sun exposure. ${ }^{1,8}$

\section{Patients and methods}

The aim of this study was to analyze all cases of malignancies after LT in our LT center and determine the incidence, the underlying primary diagnosis, management and mortality of these patients. We performed a retrospective review of all the LT recipients between June 2001 and December 2017 at Hospital de Santa Marta - CHLC (Lisbon), the only center performing LT in Portugal. We collected the demographic data of the patients, the underlying diagnosis, type and time of LT surgery, cancer characteristics, management and outcome. We evaluated the total incidence in the period of the study. The relapses were considered the same tumor.

In this 16-year period 182 patients with end-stage lung disease underwent LT with a mean age of $46+14$ years old (yo) at the time of LT. The majority of patients underwent bilateral sequential LT $(\mathrm{n}=93 ; 51.1 \%)$. The most common underlying conditions for LT were: interstitial lung diseases (ILD) ( $\mathrm{n}=76 ; 41.8 \%)$, COPD $(\mathrm{n}=48 ; 26.4 \%)$, cystic fibrosis $(\mathrm{CF})(\mathrm{n}=27 ; 14.8 \%)$; non-CF bronchiectasis $(\mathrm{n}=18$; $9.9 \%)$ and occupational diseases $(n=9 ; 4.9 \%)$.

Our IST protocol included induction immunosuppression with polyclonal anti-thymocyte globulin (ATG) and then regular maintenance therapy with a calcineurin inhibitor (usually tacrolimus or ciclosporin as alternative), a nucleotide blocking agent (frequently mycophenolate mofetil or in alternative azathioprine) and corticosteroids.

\section{Results}

We identified a total of 14 malignancies affecting 12 patients: $66.7 \%$ of patients were male $(n=8)$ and the mean age for the first 
cancer was 53 yo (range 20-67). The mean time between LT and firs cancer diagnosis was 25 months (range $0-93$ ). The primary disorders for LT in these patients were ILD $(n=5 ; 41.7 \%)$ - mostly IPF; COPD $(\mathrm{n}=5 ; 41.7 \%)$, non-CF bronchiectasis $(\mathrm{n}=1 ; 8.3 \%)$ and bronchiolitis obliterans $(n=1 ; 8.3 \%)$. Single LT was performed in the majority of cases $(n=8 ; 66.7 \%)$.
The most common type of malignancy in this series was cutaneous squamous cell cancer $(\mathrm{n}=5 ; 35.7 \%)$ with an incidence of $2.7 \%$. The other neoplasms were: 4 PTLDs $(2.2 \%), 3$ lung cancers $(1.6 \%)$ and 2 gastric cancers $(1.1 \%)$. Table 1 summarizes the malignancies in these LT patients.

Table I Malignancies in LT Portuguese recipients

\begin{tabular}{|c|c|c|c|c|c|c|}
\hline \# & $\begin{array}{l}\text { Sex and } \\
\text { age at LT }\end{array}$ & $\begin{array}{l}\text { Primary } \\
\text { diagnosis }\end{array}$ & $\begin{array}{l}\text { Type and date } \\
\text { of LT }\end{array}$ & Malignancies (date) & Management & Follow-up \\
\hline \multirow[t]{2}{*}{ I } & Male & $\mathrm{HP}$ & $\mathrm{Bi}, 2002$ & - SCC (2010) & - Excision & Death not related \\
\hline & $47 y$ & & & - SCC relapse $(2014)$ & - Excision & \\
\hline \multirow[t]{2}{*}{2} & Male & IPF & Single, 2009 & $-\operatorname{SCC}(2013)$ & - Excision & Related death \\
\hline & $63 y$ & & & - PTLD (20I5) & $\begin{array}{l}\text { - R-CHOP complicated with } \\
\text { pneumonia }\end{array}$ & \\
\hline \multirow[t]{3}{*}{3} & Male & COPD & Single, 2012 & $-\operatorname{SCC}(2013)$ & - Excision & Related death \\
\hline & $57 y$ & & & - SCC relapse $(2014)$ & - Excision & \\
\hline & & & & $\begin{array}{l}\text { Advanced gastric ADC (20I5) } \\
\text { (Figure IA \& IB) }\end{array}$ & - Support therapy & \\
\hline \multirow[t]{2}{*}{4} & Male & COPD & Single, 2012 & $\begin{array}{l}\text { - Squamous cell lung cancer in } \\
\text { the native lung IA (20I2) (Figure } \\
\text { IC) }\end{array}$ & - Lobectomy & Death not related \\
\hline & $60 y$ & & & & & \\
\hline \multirow[t]{2}{*}{5} & Male & COPD & Single, 2012 & $\begin{array}{l}\text { Squamous cell cancer in the } \\
\text { native lung IIIB (20I5) (Figure ID) }\end{array}$ & - QT and RT & Related death \\
\hline & $62 y$ & & & & & \\
\hline \multirow[t]{2}{*}{6} & Male & IPF & Single, 2013 & $-\operatorname{SCC}(2016)$ & - Excision & Alive \\
\hline & $64 y$ & & & & & \\
\hline \multirow[t]{2}{*}{7} & Male & COPD & Single, 2014 & - PTLD (2018) & - Rituximab & Alive \\
\hline & $55 y$ & & & & & \\
\hline \multirow[t]{2}{*}{8} & Female & COPD & Single, 2015 & - Advanced & - Support therapy & Related death \\
\hline & $63 y$ & & & Gastric ADC (20I5) & & \\
\hline \multirow[t]{2}{*}{9} & Female & OB & $\mathrm{Bi}, 2016$ & - PTLD (2017) & - Rituximab & Good response \\
\hline & $23 y$ & & & & & Alive \\
\hline \multirow[t]{2}{*}{10} & Male & IPF & Single, 2016 & $-\operatorname{SCC}(2018)$ & - Excision & Alive \\
\hline & $57 y$ & & & & & \\
\hline \multirow[t]{2}{*}{ II } & Female & NQFB & $\mathrm{Bi}, 2017$ & - PTLD (20।8) & - Rituximab & Good response \\
\hline & $20 y$ & & & & & Alive \\
\hline \multirow[t]{2}{*}{12} & $\begin{array}{l}\text { Female } \\
44 y\end{array}$ & $\mathrm{LCH}$ & $\mathrm{Bi}, 2017$ & - Incidental ADC explanted & $\begin{array}{l}\text { - Bone RT and } \\
\text { support therapy }\end{array}$ & Alive \\
\hline & & & & lungs IV (20I7) & & \\
\hline
\end{tabular}

LT, lung transplantation; $y$, years old; HP, hypersensitivity pneumonitis; Bi, bilateral LT; SCC, squamous cutaneous cancer; IPF, idiopathic pulmonary fibrosis; PTLD, post transplant lymphoproliferative disorders; COPD, chronic obstructive pulmonary disease; ADC, adenocarcinoma; QT, chemotherapy; RT, radiotherapy; OB, obliterative bronchiolitis; NQFB, non-cystic fibrosis bronchiectasis; LCH, langerhans cell hystiocitosis 
All cases were evaluated through a multidisciplinary approach Preferred management in skin cancer was the excision of the tumor while in PTLD was chemotherapy (rituximab in 3 and R-CHOP in the other one because of the aggressiveness of disease). In relation to lung cancer ( 2 squamous and 1 adenocarcinoma) two cases occurred in the native lung of single LT recipients for COPD and the other was an unexpected carcinoma in the explanted lungs of a patient with Langerhans cell histiocytosis ( $\mathrm{LCH})$. All patients were former smokers. They received different therapies according to the disease stage and the performance status. Finally, we noticed 2 cases of gastric adenocarcinoma with very aggressive disease causing early death. IST was reduced in all patients except for skin cancer patients.

Despite treatment and IST adjustments, 4 patients died due to cancer $(33.3 \%), 2$ died from other causes and, at the time of this study, six patients were still alive. The median survival of these patients was 26 months (range 8-44) (Figure 1).
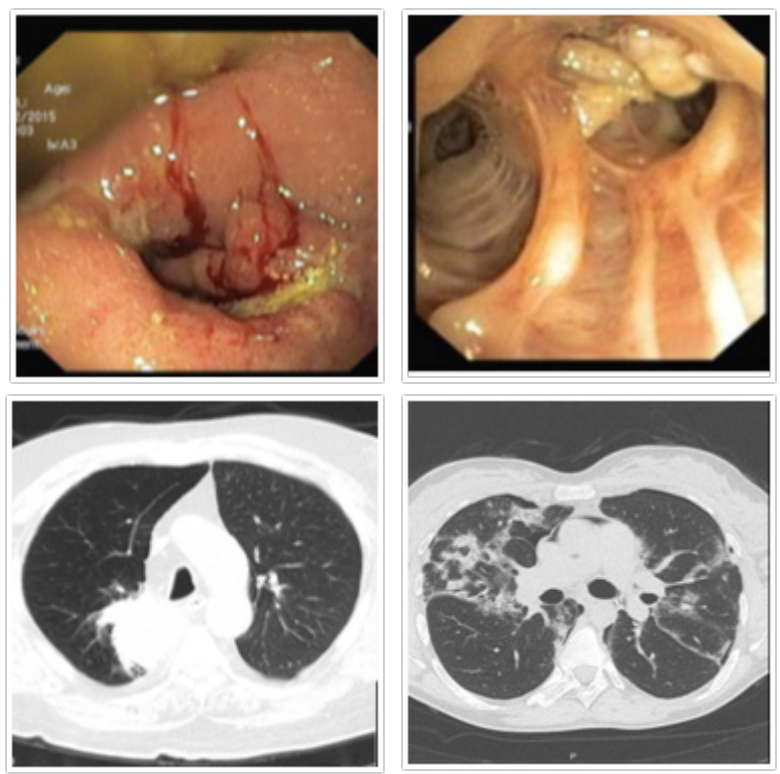

Figure I Images of images of cancer after LT. (A) Advanced gastric Adenocarcinoma (digestive endoscopy). (B) Squamous cell lung cancer stage IA (respiratory endoscopy). (C) Squamous cell lung cancer stage IIIB (CT). (D) Lung involvement for lymphoma (CT).

\section{Discussion}

This study represents the incidence, management and outcomes of malignancies in all the patients that underwent LT in Portugal. We report an incidence of $7.6 \%$ similar to others studies $(5.2 \%$ to $17 \%) .{ }^{10}$ However, this incidence may even be underestimated, as the study included all LT patients with a very short post-LT follow-up. As described by ISHLT, the most common malignancies in this series were skin cancer and PTLD. . $^{1,3,4}$

\section{Skin cancer}

In this population, skin cancer was the most frequent malignancy with an incidence of $2.7 \%$. It is known that LT recipients and their need for a three-drug regimen of IST increased the risk for skin cancer compared with two-drugs regimen. ${ }^{9}$ We registered the usual reversal with squamous cell carcinoma (SCC) being more common than basal cell carcinoma in these patients. We also noticed the elevated tumor burden and the increased risk of recurrence. ${ }^{1,11}$ Two patients developed relapses (in 1 and 4 years, respectively) and 2 patients were diagnosed with another type of cancer (PTLD and gastric). Despite SCC tends to be more aggressive in these patients, we didn't registered any case of advanced disease or any related death. ${ }^{1}$

\section{PTLD}

PTLD is a serious, often fatal complication after LT and other solid organ transplantation. ${ }^{1}$ The incidence of $2.2 \%$ is in agreement with that described in other series (1.8-20\%). ${ }^{1,11}$ PTLD is particularly frequent in the first year post-LT $T^{1,4}$ and half of our patients $(n=2$; $50 \%$ ) developed PTLD within this period. We related 2 monomorphic PTLD, 1 polymorphic and 1 undefined and the affected sites were lung $(\mathrm{n}=2)$; gastrointestinal tract $(\mathrm{n}=1)$ and bone marrow $(\mathrm{n}=1)$.

According to the literature, oncogenic viruses played an important role in the development of PTLD. ${ }^{1,2,9}$ Only one patient had previously EBV infection and that seems to increase the risk. Age is also an important risk factor in both extremes: young age increases the incidence probably because of EBV-seronegative status and older age increased the risk in relation with immune senescence. ${ }^{1}$ In line with this, we noticed 2 cases of PTLD at younger age with an average of 22 yo (and EBV seronegative status) and 2 cases of PTLD in patients older than 55 years. As in other series, treatment was most effective in the early stages. Rituximab is the first line therapy in these patients and success of this therapy has been reported. ${ }^{1}$

\section{Lung cancer}

The incidence of lung cancer in this report was $1.6 \%$, similar to other studies ranging between $0.25 \%$ and $8.9 \%$. All cases were nonsmall cell lung cancer. ${ }^{1,3,12}$ The 2 cases of lung cancer in the native lung occurred in COPD patients that underwent single LT. The occurrence of this type of cancer is in relation with the elevated prevalence of COPD and IPF patients as LT recipients, diseases that are independent risk factors for cancer and that share common occupational and environmental risk factors. ${ }^{9}$ Besides that, the diagnosis of lung cancer prior to LT is difficult because of the confounding factors in radiologic tests and the severe respiratory failure that makes some diagnostic techniques, such as bronchofibroscopy more challenging. ${ }^{13}$ It is also known that single LT recipients have a 5.3 fold increased risk of lung cancer compared with bilateral LT recipients. ${ }^{1}$

The only early stage lung cancer was diagnosed in a post-LT bronchoscopy. Some works referred the elevated incidence of lung cancer diagnosis at the time of surgery or postsurgery. ${ }^{3}$ Furthermore, surgery with curative intent seems to be an adequate procedure in these patients with very limited disease. ${ }^{3}$ Although the better way of screening this particular risk group remains unclear, we need to be more aggressive in this searching in single LT patients. ${ }^{12}$

We also reported one case of non-mutated lung adenocarcinoma (EGFR and ALK negative, no PD-L1 expression) incidentally found in end-stage LCH. This finding is similar as described in a recent literature review from $2018^{13}$ that observed adenocarcinoma as being the most common type of lung cancer and ILD as the most frequent primary disorder in this scenario. Some series reported an incidence of $1.4 \%{ }^{1}$

Because of the extensive metastatic disease in this patient and recurrent infections, she underwent only IST adjustment and support therapy - with bone radiotherapy and integrated palliative care team 
evaluation. This highlights the particular management of stage IV lung cancer in these patients and poor prognosis - with an increased risk for infections, renal failure or drug interactions with the cytostatic chemotherapy, frequently limiting more invasive intervention. ${ }^{1,3,12}$

\section{Rare malignancies}

Nevertheless, we found an unexpected important incidence of gastric cancer $(1.1 \%)$, not previously described in other series. We had two cases of gastric adenocarcinoma in two former smokers with COPD at 1 and 3 years after LT. One of the patients was proposed for gastrectomy, however, intraoperatively he presented with extensive disease without possibility for curative intent. In the other patient was decided to perform palliative chemotherapy but she evolved with clinical fast deterioration progressing to support therapy. These cases illustrated the aggressiveness and extension of the disease.

We interpreted these two unusual cases of gastrointestinal cancer with racial differences and the higher incidence of this type of cancer in Portugal. ${ }^{14,15}$ It also made us think about the eventual need for digestive endoscopic study before LT and perhaps further implementation of a protocol for follow-up after LT.

\section{Other problems and limitations}

It might be surprising that LT recipients, with a tight follow-up and clinical evaluation, presented with advanced malignant disease. However, the lack of early detection is similar in the literature. ${ }^{3}$ These results suggest that we need more effective screening modalities for the detection of cancer in these patients, in an earlier stage.

This report has several limitations. First, although the number of patients that underwent LT in Portugal is increasing in the last years (actually 30/year), this small sample reflects the low number of LT in the beginning years. Therefore, the follow-up period for most of the patients is short. At the moment of this study, 4 patients had the diagnosis of cancer less than a year ago. This is an important bias in this report because, as stated by the ISHLT, malignancy incidence increases after 5 years of LT. ${ }^{4}$ Secondly, in relation with this learning curve and the recent history of this LT center, we still had an important number of single LT in COPD and IPF patients, which is known to increase the risk for lung cancer. ${ }^{3}$ Finally, being a retrospective analysis we also have to notice that the management practices in oncology have evolved and are changing the prognosis of malignant disease.

\section{Conclusion}

Malignancy is an important cause of morbidity and mortality after LT. We conclude that awareness for this problem must increase, not only in order to create screening protocols for the commonest types of cancer, but also to ensure a careful evaluation of clinical data. We need randomized control trials and established recommendations about IST adjustment and therapeutic interventions in this special population. This report also reinforces the need to improve the gastrointestinal cancer screening in the Portuguese LT recipients.

\section{Acknowledgments}

None.

\section{Conflicts of interest}

The authors declare there are no conflicts of interest.

\section{References}

1. Robbins H, Arcasoy S. Malignancies following lung transplantation. Clin Chest Med. 2011;32(2):343-355.

2. Rothmaier S, Haydon AM, Loi S, et al. Incidence of malignancies in heart and/or lung transplant recipientes: a single-institution experience. $J$ Heart Lung Transplant. 2007;26(8):845-849.

3. Pérez-Callejo D, Torrente M, Parejo C, et al. Lung cancer in lung transplantation: incidence and outcome. Postgrad Med J. 2018;94(1107):15-19.

4. Lund LH, Khush KK, Cherikh WS, et al. The registry of the International Society for Heart and Lung Transplantation: 34th adult lung and heartlung transplantation report-2017; Focus Theme: Allograft ischemic time. J Heart Lung Transplant. 2017;36(10):1037-1146.

5. Ekström M, Riise GC, Tanash HA. Risk of cancer after lung transplantation for COPD. Int J Chron Obstruct Pulmon Dis. 2017;12:2841-2847.

6. Ordóñez Dios IM, Montoro Ballesteros F, Vaquero Barrios JM, et al. Analysis of the incidence of noncutaneous neoplasia after lung transplantation and its impact on prognosis. Transplant Proc. 2015;47(9):2659-2660.

7. Stehlik J, Edwards LB, Kucheryavaya AY, et al. The registry of the International Society for Heart and Lung Transplantation: 28th adult lung and heart-lung transplant report-2011. J Heart Lung Transplant. 2011;30(10):1078-1094.

8. Raviv Y, Shitrit D, Amital A, et al. Lung cancer in lung transplant recipients: experience of a tertiary hospital and literature review. Lung Cancer. 2011;74(2):280-283.

9. Olland A, Falcoz PE, Massard G. Malignancies after lung transplantation. $J$ Thorac Dis. 2018;10(5):3132-3140.

10. Miyazaki T, Oto T, Okumura M, et al. De novo malignancy after lung transplantation in Japan. Gen Thorac Cardiovasc Surg. 2016;64(9):543548.

11. Schettini-Soares M, Júnior OG, Costa HF, et al. Incidence and mortality by cancer in patients after lung transplantation in a brazilian institution. Transplant Proc. 2017;49(4):882-885.

12. Yserbyt J, Verleden GM, Dupont LJ, et al. Bronchial carcinoma after lung transplantation: A single-center experience. J Heart Lung Transplant. 2012;31(6):585-590.

13. Panchabhai TS, Arrossi AV, Patil PD, et al. Unexpected neoplasms in lungs explanted from lung transplant recipients: a single-center experience and review of literature. Transplant Proc. 2018;50(1):234 240 .

14. Ferlay J, Steliarova-Foucher E, Lortet-Tieulent J, et al. Cancer incidence and mortality patterns in Europe: estimates for 40 countries in 2012. Eur J Cancer. 2013;49(6):1374-1403.

15. Carvalho F, Peixoto A, Steffensen R, et al. MUC1 gene polymorphism does not explain the different incidence of gastric cancer in Portugal and Denmark. Ann Hum Genet. 1999;63(Pt 3):187-191. 